\title{
ÉTICA Y PERIODISMO DE INFORMACIÓN ECONÓMICA
}

\section{Mauricio Galindo Caballero}

\section{RESUMEN:}

En este artículo el autor participa de los tropiezos que demarca la tarea de informar, teniendo en cuenta que la opinión refleja diferentes comportamientos frente a determinada noticia. Es decir, si una noticia es mala, el periodista es visto por muchos como "el culpable de ella" y no como la persona que tiene la misión de informar a las audiencias. Asímismo, este documento hace referencia a los dilemas éticos que enfrenta un periodista; los cuales son de dimensiones insospechadas, teniendo en cuenta que quien arroja una noticia tiene un compromiso social que está por encima aún de intereses propios; de forma tal, que el informante debe resistir cualquier criterio ajeno a la imparcialidad, la objetividad y sobretodo la verdad.

\section{ABSTRACT:}

In this article, the author is part of the obstacles deriving from the informing task, considering that opinion reflects different behaviors with respect to a specific piece of news. That is, if a piece of news is bad, the journalist is regarded by many as "guilty for it" and not as the person with the unique mission of informing audiences. Likewise, this document makes reference to the ethical dilemmas faced by a journalist which reach unsuspected dimensions, taking into account that when releasing a piece of news; he takes on social commitment above his own interests. The communicator has to reject any criterion different from impartiality, objectivity and, truth above all.

\section{PALABRAS CLAVE:}

Calibres; conglomerado; recesión.

\section{KEYWORDS:}

Calibers; conglomerate; recession.
En ocasiones, muy frecuentes por cierto, los periodistas son blanco del desahogo de las frustraciones de la sociedad. El caso típico cuando el portador de las malas noticias es sacrificado. Y el fenómeno se acentúa en la medida en que hay mayor interacción con las audiencias a través de internet.

Por ejemplo, los periodistas sobre economía reciben a diario mensajes con quejas de diversos calibres donde resultan responsables o cómplices de la inflación, el desempleo, el déficit fiscal, la lluvia que echó a perder los paseos dominicales, la deva- luación o la revaluación o la forma como se está enajenando el país a pedacitos.

Una racha de este tipo de mensajes se desencadenó luego de la publicación en $E l$ Tiempo (lunes 22 de agosto de 2005) de la noticia: "Advierten que precios de las acciones son irreales". En resumen, esa noticia contaba que en los últimos cuatro años, en promedio, las acciones que se transan en la Bolsa de Colombia se habían valorizado casi $800 \%$. Es decir, que quienes compraron acciones en la bolsa en enero del año 2001 y las conservaban en ese momento, por cada 
Para ver cómo la actividad del periodista encaja en la dinámica económica, es útil echar una mirada general a esa dinámica: la vida económica de la sociedad es todo ese conjunto de actividades con las que la gente busca mayor acceso a los bienes y servicios disponibles en el mercado para obtener bienestar. millón de pesos invertido podían tener casi nueve millones de pesos. Pero, y es ahí donde está la noticia, los análisis de dos importantes instituciones, la Asociación Nacional de Instituciones Financieras (ANIF) y el Fondo de Pensiones Porvenir, decían que las acciones podían haber subido a precios ficticios, y que quienes compraran acciones debían ser conscientes de los riesgos en los que estaban incurriendo.

Un día después de la publicación en $E l$ Tiempo, el tema fue publicado también en dos periódicos especializados en economía, y hubo una caída de los precios de las acciones en la bolsa de 4\%, acompañada de mensajes por correo electrónico a la Redacción de El Tiempo donde tildaban a los periodistas de irresponsables, e incluso se hacían insinuaciones sobre algún interés suyo de que los precios de las acciones cayeran.

Evidentemente, todo lo que sucedió luego de publicarse esta noticia era previsible. Era de esperarse que la bolsa pudiera bajar el día en que se publicaran los análisis de esas dos instituciones. Y las quejas por el correo electrónico eran todavía más fáciles de predecir. Por lo tanto, en las decisiones necesarias para llegar a hacer esta publicación había al menos un dilema ético que se resolvió con la decisión de publicar la historia. Este episodio hace parte de las

\section{RESEÑA DE AUTOR}

Mauricio Galindo Caballero. Es Comunicador de la Pontificia Universidad Javeriana y Economista de la Universidad de La Salle y editor de Económicas del diario El Tiempo. Ha sido Jefe de Redacción del diario Portafolio, reportero de El Tiempo y El Espectador, docente de la Universidad Javeriana y del Politécnico Grancolombiano, y ha trabajado en investigación en las universidades Javeriana y de los Andes y en consultoría para el Banco Interamericano de Desarrollo.

galmau@eltiempo.com.co rutinas diarias, cotidianas, del periodismo económico, y permite iniciar con una visión práctica unas reflexiones sobre la dimensión ética del trabajo en esta clase de periodismo.

\section{EL PERIODISTA Y LA DINÁMICA ECONÓMICA}

Para la ética del periodista en Economía hay un punto de especial importancia y es su papel de informador para la sociedad, desempeñado desde una empresa privada que, además, probablemente es parte de un conglomerado económico. El periodista es simultáneamente eso, un informador, pero, además, un actor de la vida económica, como empleado, consumidor, trabajador, miembro de una familia. Es decir, integrado, como todas las personas, a la dinámica económica, pero con la responsabilidad especial de contar sobre ella.

Para ver cómo la actividad del periodista encaja en la dinámica económica, es útil echar una mirada general a esa dinámica: la vida económica de la sociedad es todo ese conjunto de actividades con las que la gente busca mayor acceso a los bienes y servicios disponibles en el mercado para obtener bienestar.

Allí, el valor que se persigue es la utilidad, que puede ser individual o puede ser colectiva. No olvidemos que la disciplina económica creada hace más de 200 años por Adam Smith tenía una carga individualista, pero en las últimas décadas los investigadores económicos, entre ellos varios premios Nobel, han rescatado el papel de defensor de valores colectivos como la solidaridad.

En general, los economistas suponen que todos los fines económicos deseables se logran más fácilmente si hay crecimiento de la producción. En consecuencia, 
el deber del comportamiento económico de la colectividad es el crecimiento, en función de la utilidad individual y del bienestar social. En la búsqueda de esos fines actúan agentes individuales y otros, institucionales, que deben propiciar las condiciones del crecimiento, la utilidad y el bienestar. Esos agentes institucionales son, por ejemplo, las autoridades económicas: el Ministerio de Hacienda, el banco central. Pero la prensa, y los medios de información en general, también son parte de este elenco de agentes institucionales. Por esa razón, los periodistas económicos terminan jugando un papel doble como ciudadanos, con sus intereses privados, y como agentes institucionales de la vida económica, en la que se supone que deben actuar en función de intereses colectivos.

\section{LA PRENSA, UN AGENTE INSTITUCIONAL}

Decir que los medios de información son un agente institucional dentro de la dinámica económica merece, al menos, una explicación: El crecimiento económico, el deber ser de todas esas cosas que hacemos como agentes económicos, depende de las decisiones de los agentes; de que inviertan, de que consuman, de que den empleo. En resumen, de que tomen riesgos.

¿Por qué estarían en disposición de tomar riesgos? Depende de algo que economistas y no economistas llaman "confianza”.

El ritmo de la actividad económica lo marca la manera como personas y empresas gastan. Las personas gastan en lo que consumen y las empresas gastan en los negocios que emprenden, es decir, en lo que invierten. $Y$ las decisiones de consumir o invertir dependen de las expectativas y de la confianza que tengan. Y estas expectativas y el clima de confianza se forman con base en la información que reúnen personas y empresas.

Es ahí donde el periodismo interviene y cumple un papel en la actividad económica.

Buena parte del volumen de señales, datos e información en general que reciben personas y empresas, lo obtienen en los medios de información. Y esa información contribuye a la formación de expectativas; es decir, las creencias que tienen las personas sobre lo que en el futuro les pasará a realidades difícilmente predecibles, pero que las afectan como las tasas de interés, los precios o la seguridad personal. Con base en esa misma información, crece o disminuye la confianza, o sea, el grado de convencimiento de que las condiciones favorables o deseadas se presentarán en la realidad.

La confianza es tan importante que, cuando la gente se siente segura, puede sentir que sus propiedades valen más. Y cuando la gente se siente rica se comporta como rica.

Creerse rico puede enriquecer. ¿Cómo es eso? Quien se siente rico gasta más. Y si ese sentimiento es colectivo, cuando las personas gastan más, las empresas deben producir más, usar más sus instalaciones y sus tierras y dar más trabajo. La consecuencia de todo esto es que, efectivamente, la sociedad será más rica. Este fenómeno lo identificó hace varias décadas Pigou y se conoce como "efecto riqueza".

Parece la descripción del efecto en la economía de un delirio colectivo. Sin embargo, se pueden ver casos del efecto riqueza en la vida real, como en la expansión económica de Estados Unidos durante 
una década. El crecimiento económico de ese país, entre marzo de 1991 y marzo de 2001 fue impulsado en gran parte por la confianza. Por esa razón, gastaban más y más al sentir que sus propiedades representaban riqueza de manera segura. Los precios de sus pertenencias, como casas o acciones, aumentaban. En particular, las acciones tuvieron un papel muy importante en esa época de bonanza económica, pues la mitad de las familias estadounidenses tenían parte de sus ahorros invertidos en ellas, y en la segunda parte de la década de los 90 los precios de esos títulos subieron como pocas veces se había visto. Según el Sistema de la Reserva Federal (el banco central de Estados Unidos), en 1999 las acciones en manos de las familias valían 164\% de lo que valían en 1995 .

Si en 1985, de cada cien dólares que se podían gastar, los estadounidenses ahorraban casi diez dólares, en el 2001 sólo ahorraron dos dólares con 30 centavos, y consumieron 97 con 70. ¡Eso es tenerse confianza! Gracias a esa confianza, la recesión del año 2001, que comenzó medio año antes de los atentados contra las Torres Gemelas, se superó rápidamente y se neutralizaron en parte los efectos del ataque terrorista.

Claro. En un medio como Colombia, ahorrar poco o no ahorrar no se puede interpretar necesariamente como señal de confianza, sino que es consecuencia de que para muchos el ingreso a duras penas alcanza para lo esencial.

Pero así como se puede hablar de un efecto riqueza, también debe haber un efecto pobreza, determinado también por la información que leen y escuchan los consumidores y los empresarios.
Cuando las personas y las empresas sienten que sus propiedades valen menos, cada cual seguramente ahorrará más y consumirá menos. Una fábrica de café puede decidir que no permitirá a sus empleados hacer llamadas telefónicas personales, mientras la empresa de teléfonos decide, por su parte, no darle a sus trabajadores más café en sus descansos. Mientras tanto, las personas en sus casas pueden decidir beber menos café y usar menos el teléfono. El resultado final es que todas las medidas que toman las personas y las empresas para defender su ingreso no tienen efecto alguno. Lo que ahorró la empresa de teléfonos en café y en otras cosas, posiblemente, es igual a las llamadas que las otras empresas y las personas dejaron de pagarle. Y si las familias reducen su consumo, probablemente, lo que están haciendo es forzar a las empresas a que despidan a los jefes de hogar. Adicionalmente, si todas las empresas despiden trabajadores para disminuir sus pérdidas, éstas no disminuirán pues la gente les comprará menos.

Este efecto pobreza es una muestra de cómo la búsqueda del bienestar individual puede traer el malestar de toda la sociedad, exactamente al contrario de lo que predicaba Adam Smith.

\section{UN PAR DETENTACIONES}

Detrás de todos estos ejemplos reales o hipotéticos, de cómo la confianza y las expectativas contribuyen a decidir la suerte de la economía, está la información: desde datos escuetos hasta análisis, interpretaciones, opiniones y señales más sofisticadas, transmitidos por los medios de comunicación.

Si la información económica y no económica de los medios de comunicación 
contribuye a la formación de las expectativas y del clima de confianza y por lo tanto, influye en la toma de decisiones, entonces se podría pensar que la prensa económica, en general, podría contribuir a mantener la confianza, y, en particular, en tiempos de crisis podría ayudar a reanimar a empresarios y consumidores para gastar y reactivar el sistema.

Con esta lógica, se podría caer en la tentación de privilegiar las señales positivas sobre las negativas. Por supuesto que ese no puede ser el papel, pues la transmisión de las señales negativas permite que los agentes tomen precauciones. Claro, esas precauciones, que generalmente consisten en invertir y consumir menos, pueden precipitar las crisis, pero en una situación contraria, las señales contribuirán a precipitar la recuperación.

Sin embargo, si las señales correctas llevan a decisiones que precipiten una crisis, esto sería preferible a distorsionar señales que prolonguen artificialmente el crecimiento económico, pues en este caso de todas maneras, vendrá la caída, pero será más aparatosa. El efecto riqueza del que se habló antes sólo se puede sostener sobre bases reales.

En este caso, la responsabilidad del periodismo económico es enviar señales claras, y fieles a los hechos detectados en la realidad. Aún en caso de crisis, y así sea previsible que las señales negativas que se envíen llevarán a que se tomen decisiones que frenen o hagan caer más la producción. En caso de crisis, privilegiar señales positivas o distorsionar las señales negativas podría llevar a que los empresarios más débiles tomen decisiones equivocadas, mientras que los empresarios más fuertes, que tienen acceso a distintas fuentes de información más allá de los medios masivos, que tienen la posibilidad de contrastar esa información, y los recursos para procesar e interpretar por cuenta propia la información reunida, consoliden sus ventajas a costa de los más débiles. Intentar crear confianza mediante información distorsionada no logra animar a todo el sector productivo para emprender el camino de una reactivación económica y, en cambio, quizá sólo empuje a los empresarios más débiles y vulnerables a tomar riesgos injustificados. Solamente se ahondarían las asimetrías en la información disponible.

Pero si puede existir la tentación, en medio de la crisis, de privilegiar las señales positivas, también puede existir la tentación, exactamente contraria, de servir de caja de resonancia de todo lo negativo. En el primer caso, por lo menos se perseguía aparentemente el beneficio colectivo de querer contribuir a un clima más favorable para contrarrestar la crisis. Pero el segundo caso persigue sólo los supuestos beneficios inmediatos y privados que se esperan de titulares sensacionalistas.

Pero esa práctica, que puede generar alguna venta adicional de ejemplares o alguna sintonía extra, puede devolverse contra el medio que la adopte. Para quien se desayuna mientras lee, y se encuentra con una visión sistemáticamente negativa, será muy fácil abandonar esas lecturas. ¿Para qué pagar por algo cuyo fin primordial es amargar el día desde la primera hora?

\section{COMPROMISO CON EL LENGUAJE}

Probablemente no es la información producida por el periodismo económico la que tiene un mayor impacto en la forma-

\section{La}

responsabilidad del periodismo económico es enviar señales claras, y fieles a los hechos detectados en la realidad. 
ción de expectativas y en la construcción o el derrumbe de la confianza para los negocios. Tienen más impacto en el clima de los negocios las noticias políticas, judiciales y de hechos generales.

Lo anterior, porque para los consumidores y para los empresarios decidir si se compra o se invierte y qué se compra o en qué se invierte es parte de la vida diaria. Son hechos concretos y cotidianos. Y la información política o las páginas y secciones dedicadas a los hechos nacionales, a los hechos judiciales y de orden público muestran justamente hechos concretos que afectan directamente la cotidianidad.

En cambio, hay una percepción, por supuesto equivocada, presente incluso entre hombres y mujeres de negocios, de que la información económica no habla de la vida misma. Esto, por cuanto los hechos económicos no siempre se manifiestan directamente, sino que es necesario un trabajo adicional de lectura de la realidad, alguna mediación operativa. El déficit fiscal no es algo que esté en la casa de los lectores. Muchos de los hechos económicos son abstracciones de la realidad, y por lo tanto se nombran con un lenguaje igualmente abstracto, alejado de la sensibilidad cotidiana.

En nuestra casa puede vivir algún desempleado, pero cuando esa realidad se observa a través de una tasa, de una proporción matemática, comienza a alejarse.

La información periodística económica debería tener un impacto mayor al que aparentemente tiene en la construcción de expectativas y del clima de confianza de empresarios y consumidores. El acopio de información de los agentes puede ser desequilibrado, pues si los agentes reciben señales concretas negativas desde la información periodística política o de orden público, podrían recibir señales positivas sobre la respuesta de las autoridades económicas. Sin embargo, como se trata de una realidad que se digiere con mayor dificultad, la visión de la realidad con que las personas forman sus expectativas se hace con base en la comprensión desigual de los distintos factores que las afectan.

Si por ejemplo, los hechos concretos y de comprensión más fácil son positivos, pero las señales económicas son negativas, podría suceder que las personas tomaran menos precauciones en sus decisiones económicas.

Eso pudo haber pasado en el auge de la construcción de vivienda a mediados de los años 90 que desembocó en la quiebra masiva de familias y en la peor recesión económica documentada en Colombia. Los hechos concretos apuntaban a la tranquilidad, mientras las señales económicas apuntaban a que había una burbuja especulativa en torno al negocio de la vivienda, que terminaría reventándose. Sin embargo, estas señales eran más difíciles de discernir por la gente a pesar de tener acceso a esa información. Así, millares de familias tomaron decisiones equivocadas orientadas por información que, aunque estaba disponible, no era tan comprensible como las señales provenientes de la información periodística no económica.

Salta, entonces, una tarea primordial de los periodistas económicos, y es acercar los hechos de los que hablan a la comprensión de la gente.

El papel de la información económica de los medios no puede ser entonces, darle ánimo a la economía por que sí. Como 
esos motivadores profesionales que se han tomado de ciertos textos de administración. El efecto en la realidad de las señales distorsionadas puede ser catastrófico. El papel es llevar las señales negativas o positivas con la mayor fidelidad posible y de la manera más clara para que sean comprendidas en toda su dimensión por la personas.

\section{TODO APUNTA AL LECTOR}

Como se ve, todo desemboca en la lealtad con el lector. Quizá ese es uno de los principales puntos del marco ético dentro del que se desempeña el periodismo. Así se refleja, por ejemplo, en el Manual de Redacción de El Tiempo (Bogotá: Casa Editorial El Tiempo, 2002): El lector es la prioridad... El trabajo del periodista está en función del derecho a la información que tienen sus audiencias... Debe haber transparencia con los lectores y garantías para su participación... Los errores se deben corregir con claridad y oportunidad... La jefatura de Redacción es autónoma frente a quienes manejan la venta de publicidad...

Además, hay un valor esencial en este oficio: la voluntad de sospecha. Porque alrededor revolotea una legión de poderes que desean que la prensa sea su instrumento: el poder institucional, pero también los poderes de hecho, empresas y conglomera- dos privados, gremios, interesados en grandes negocios en ciernes. ¿El propio medio, posiblemente, no es parte de un conglomerado con intereses más allá del negocio de la comunicación?

No se trata de erigir murallas para evitar que los representantes de todas estas instancias se acerquen. Porque, por un lado, se debe asumir que sus intereses son legítimos, y, por otro, no se debe descartar, de entrada, que probablemente traigan información valiosa, útil e interesante para las audiencias.

Es necesario escucharlos a la espera de esa información valiosa, o incluso, ir a ellos. Pero con el presupuesto de que es información parcial. Y es deber del periodista completarla, convertirla en información plena e ir por los otros fragmentos que están en manos de otras fuentes.

Si se trata de no ser instrumento de los intereses de un tercero, el escudo está conformado por los principios básicos. En el Manual de Redacción de El Tiempo se sintetizan así: veracidad... objetividad... imparcialidad... oportunidad... orientación... resistencia a la manipulación... Y teniendo en cuenta permanentemente esta idea: "Aún los más pequeños dilemas de criterio tienen una dimensión ética". 